\title{
Development and validation of high-performance liquid chromatography method for simultaneous determination of acyclovir and curcumin in polymeric microparticles
}

\author{
Jéssica Brandão Reolon', Maicon Brustolin', Sandra Elisa Haas', Eduardo André Bender', Marcelo Donadel Malesuik', \\ Letícia Marques Coloméi* \\ 'Programa de Pós-graduação em Ciências Farmacêuticas, Universidade Federal do Pampa - UNIPAMPA, Uruguaiana, RS, Brasil.
}

\begin{tabular}{|c|c|}
\hline ARTICLE INFO & ABSTRACT \\
\hline Article history: & \multirow{6}{*}{$\begin{array}{l}\text { This study aimed to develop and validate a HPLC based analytical methodology for simultaneous determination of } \\
\text { acyclovir and curcumin within microparticles. Chromatographic separation was achieved by employing a Fenomenex } \\
\text { C18 column as stationary phase and a ternary mixture of acetonitrile, } 0.1 \% \text { phosphoric acid, and methanol }(50: 40: 10) \\
\text { as the mobile phase. The validated method proved to be linear in the range of } 0.5-30 \mu \mathrm{g} \cdot \mathrm{mL}^{-1} \text { and } 0.5-20 \mu \mathrm{g} \cdot \mathrm{mL}^{-1} \\
\text { for acyclovir and curcumin, respectively. Detection and quantification limits for acyclovir were, respectively, } 83.62 \\
\text { ng.mL } \mathrm{mL}^{-1} \text { and } 109.52 \mathrm{ng} \cdot \mathrm{mL}^{-1} \text {, while for curcumin the values were } 91.61 \mathrm{ng} \cdot \mathrm{mL}^{-1} \text { and } 128.71 \mathrm{ng} \cdot \mathrm{mL}^{-1} \text {, what assures } \\
\text { the methodology sensitivity. The method was also precise }(1.2 \% \mathrm{RSD} \text { for acyclovir and } 1.38 \% \mathrm{RSD} \text { for curcumin), } \\
\text { besides showing recovery rates close to } 100 \% \text { for both of two drugs when accuracy was accessed. Minor alterations } \\
\text { over chromatographic setup have confirmed methodology robustness. The present methodology proved to be capable } \\
\text { of detecting and quantifying acyclovir and curcumin at polymeric microparticles in a single run, showing itself as an } \\
\text { analytical alternative to be employed in the quality control for this dosage form. }\end{array}$} \\
\hline on: $21 / 11 / 2017$ & \\
\hline $01 / 2018$ & \\
\hline Available online: $28 / 01 / 2018$ & \\
\hline & \\
\hline $\begin{array}{l}\text { Key words: } \\
\text { HPLC method validation, } \\
\text { acyclovir, curcumin, micro- } \\
\text { particles. }\end{array}$ & \\
\hline
\end{tabular}

\section{INTRODUCTION}

\section{Acyclovir}

(9-[2-Hydroxy-ethoxy-methyl]guanine) (ACV) (Fig. 1) was discovered in 1977 and, at that time, it was seen as the beginning of a new age for infection treatment caused by herpes simplex family viruses (Field and Vere Hodge, 2013). Among the available therapeutic options for palliative treatment of human herpes simplex caused infections. ACV is the drug of first choice, once it has great efficiency and safety against in healing both HSV-1 and 2 caused lesions (Gandhi et al., 2014).

Curcumin (1,7-bis[4-Hydroxy-3-methoxyphenyl]-1, 6-heptadiene-3,5-dione) (CUR) (Fig. 2) is a natural compound extracted from Curcuma Longa L. rhizome, which has showed numerous therapeutic properties, among them are antiparkinson, antineoplastic, anti-inflammatory, antioxidant, antibacterial, anti-

\footnotetext{
${ }^{*}$ Corresponding Author

Letícia Marques Colomé; BR472, Km592, Uruguaiana, RS, Brazil, CEP 97501-570.E-mail: leticiacolome @ unipampa.edu.br
}

fungal, and antiviral (Joshi, 2010; Zandi et al., 2010; Yallapu et al., 2012; Mandal, 2017).

In view of CUR potential antiviral activity against herpes family virus (Zandi et al., 2010), and the increasing occurrence of viral resistance mechanisms, it may be beneficial to associate different antiviral drugs. As an example of the aforementioned, ACV associated with CUR can potentialize their antiviral activity.

However, these two drugs have limitations in their use. When orally administered, ACV presents several limitations, such as low solubility in water, short half-life, and a high rate of renal excretion. Those features compromise ACV bioavailability, which is around 15-30\% (Stulzer et al., 2008; Saxena, 2011). Similarly, CUR has low water solubility, compromising its oral usage (Moorthi, 2013b; Tung, 2017).

In the light of those aforementioned therapeutic hindrances surrounding ACV and CUR use, pharmaceutical technology techniques have been employed in order to solve such problems. Among them, polymeric microparticles are applied 
with great success in obtaining controlled-release systems, improving solubility and stability of different molecules (Shahani and Panyam, 2011; Martins, 2013; Gandhi et al., 2014).

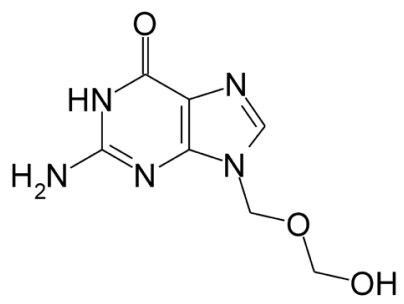

Fig. 1: Acyclovir chemical structure.<smiles>COc1cc(/C=C/C(=O)CC(=O)/C=C/c2ccc(O)c(OC)c2)ccc1O</smiles>

Fig. 2: Curcumin chemical structure.

Aiming the active ingredient determination in different pharmaceutical dosage forms, numerous analytical methodologies are proposed. Many of these methods are based on high-efficiency liquid chromatography (HPLC). HPLC-PDA based methodologies are already described for ACV and its impurities determination (Tzanavaras and Themelis, 2007), as well as ACV determination in urine, plasm, amniotic fluid, fetal and placental tissues (Land and Bye, 1981; Brown et al., 2002; Fernandez et al., 2003). Besides that, quantification methods were developed for ACV determination in tablets (Ghosh et al., 2012) and microparticulate drug delivery systems (Stulzer et al., 2008).

Similarly to ACV, CUR also has many determination methods already described in the literature, where some of them aim to simultaneously measure CUR and others curcuminoids employing HPLC based techniques (Jayaprakasha et al., 2002; Wichitnithad et al., 2009). Moorthi and co-workers (Moorthi, 2013b; Moorthi, 2013a) have developed analytical methodologies to simultaneous determination of CUR, quercetin, and piperine, all of them coencapsulated as a nanoparticulate drug delivery system. Additionally, pharmacokinetic evaluation was also conducted by determining CUR orally administered as liposomes to rats (Li et al., 2009).

Although the existence of numerous studies that developed and validated determination methods for those drugs, there is not one that is capable to determine both of them in a single run. Thus, this study main objective was to develop and validate a HPLC-based analytical method to simultaneously determine ACV and CUR in polymeric microparticles, following the official guidelines from The International Conference on Harmonisation of Technical Requirements for Registration of Pharmaceuticals for Human Use (ICH, 2005).

\section{MATERIALS AND METHODS}

\section{Chemicals}

ACV (98.32\% purity) was obtained from Pharma Nostra (Brasil). CUR (65\% purity) was obtained from Sigma (Brasil). Hydroxypropyl methylcellulose E-4000 (HPMC E4000 ${ }^{\circledR}$ ) was obtained from Galena (Brasil). Ammonium methacrylate copolymer (Eudragit RS100 ${ }^{\circledR}$ ) was obtained from Evonik Röhm (Brasil). Manitol was obtained from Gemini (Brazil). Acetonitrile (ACN) and methanol $(\mathrm{MeOH})$ were HPLC grade.

\section{Equipments and chromatographic conditions}

High-efficient liquid chromatograph Proeminence ${ }^{\circledR}$ (Shimadzu) was employed for all analysis. This HPLC is equipped with a quaternary pump, automatic sampler, photo-diode array detector (PDA) and the LC software v. 1.22 SP1. Separation was obtained in a $\mathrm{C} 18$ reversed-phase column $\left(\right.$ Phenomenex ${ }^{\circledR}, 4.6 \times$ $150 \mathrm{~mm}, 5 \mu \mathrm{m})$ by making use of an $\mathrm{ACN}: \mathrm{H}_{3} \mathrm{PO}_{4} 0.1 \%: \mathrm{MeOH}$ mobile phase $(50: 40: 10 \mathrm{v} / \mathrm{v} / \mathrm{v}$ proportion) at a flow rate of 0.8 mL.min. ${ }^{-1}$. Injection volume was $20 \mu \mathrm{L}$ and column temperature was $35^{\circ} \mathrm{C}$. Both two drugs were detected at $254 \mathrm{~nm}$.

\section{ACV/CUR-loaded microparticles preparation}

The microparticles (MP) were prepared by Spray Drying technique, utilizing Büchi ${ }^{\circledR}$ B-290 Mini Spray Dryer. ACV, CUR and Eudragit RS100 ${ }^{\circledR}$ were dissolved in $5 \mathrm{~mL}$ of ethanol. A previously prepared and stocked solution $\left(4^{\circ} \mathrm{C}, 48 \mathrm{~h}\right)$ containing HPMC E4000 ${ }^{\circledR}(45 \mathrm{~mL})$ was poured over that ethanolic solution. Finally, mannitol was added and the mixture was homogenized under agitation for $10 \mathrm{~min}$, and in an ultrasonic bath for additional $20 \mathrm{~min}$. The resultant mixture was nebulized under the following conditions: $3 \mathrm{~mL} \cdot \mathrm{mL}^{-1}$ flow rate, temperature of $100^{\circ} \mathrm{C}, 40 \mathrm{kgf} . \mathrm{m}^{-2}$ drawing flow, and $1.2 \mathrm{~mm}$ width atomizer needle. The theoretical load of drugs in the obtained microparticles was $32.8 \mathrm{mg} / \mathrm{g}$ and $5.4 \mathrm{mg} / \mathrm{g}$ of ACV and CUR, respectively. To obtain a placebo, we prepared drug-free MP, which were prepared in the same way as the drug-filled MP and are called MP-Br.

\section{Standard solutions and samples preparation}

ACV stock solution ( $\left.400 \mu \mathrm{g} \cdot \mathrm{mL}^{-1}\right)$ was prepared by dissolving $10 \mathrm{mg}$ of it with a binary mixture of DMSO and ACN $(20: 80 \mathrm{v} / \mathrm{v})$ in a $25 \mathrm{~mL}$ volumetric flask. CUR stock solution (200 $\mu \mathrm{g} . \mathrm{mL}^{-1}$ ) was prepared by dissolving $10 \mathrm{mg}$ of it with $\mathrm{ACN}$ in a 50 $\mathrm{mL}$ volumetric flask. All samples were placed in an ultrasonic bath for $30 \mathrm{~min}$, aiming complete drug dissolution. Before all analysis, they were filtered in a $45 \mu \mathrm{m}$ membrane.

Sample preparation was conducted by dissolving $35 \mathrm{mg}$ of MP (equivalent to $1.148 \mathrm{mg}$ and $0.189 \mathrm{mg}$ of ACV and CUR, respectively) in a binary mixture of DMSO and ACN (20:80 v/v) in a $50 \mathrm{~mL}$ volumetric flask. Aiming for complete drug extraction from MPs, the samples were homogenized in an ultrasonic bath for $60 \mathrm{~min}$.

An aliquot of that solution $(5 \mathrm{~mL})$ was transferred into a $10 \mathrm{~mL}$ volumetric flask, which was diluted with $\mathrm{ACN}$ to give a final concentration of $11.48 \mu \mathrm{g} \cdot \mathrm{mL}^{-1}$ and $1.89 \mu \mathrm{g} \cdot \mathrm{mL}^{-1}$ for ACV and CUR, respectively. All samples were filtered under a $45 \mu \mathrm{m}$ membrane before all analysis. 


\section{Analytical methodology validation}

Analytical methodology validation was conducted according to ICH (The International Conference on Harmonisation of Technical Requirements for Registration of Pharmaceuticals for Human Use). The following parameters were evaluated: specificity, linearity, detection limit (LOD), quantification limit (LOQ), precision, accuracy and robustness.

\section{Specificity}

Methodology specificity was determined by evaluating excipients interference in ACV and CUR determination. In order to achieve that, a comparative analysis between MP-Br (drug free) and MP (drug filled) was conducted. The chromatograms of both two groups were compared to verify if there was excipient interference over drug quantification.

\section{Linearity}

Linearity was evaluated by constructing of three different calibration curves, with six points each $(0.5,1,5,10$, 20, and $30 \mu \mathrm{g} \cdot \mathrm{mL}^{-1}$ for $\mathrm{ACV}$, and $0.5,1,5,10,15$, and 20 $\mu \mathrm{g} . \mathrm{mL}^{-1}$ for CUR). Equation of the line was determined by linear regression. The linearity was evaluated by linear regression analysis, which was calculated by the least square regression method. Three calibrations curves were obtained with six concentrations each for $\operatorname{ACV}(0.5,1,5,10,20$, and 30 $\left.\mu \mathrm{g} . \mathrm{mL}^{-1}\right)$ and $\operatorname{CUR}\left(0.5,1,5,10,15\right.$, and $\left.20 \mu \mathrm{g} \cdot \mathrm{mL}^{-1}\right)$.

\section{LOD and LOQ determination}

Limits were calculated by signal-to-noise ratio by comparing both two measurements in ACV, CUR and a drugfree group. LOD was considered as a 3:1 signal-to-noise ratio, while LOQ was considered as a 10:1 signal-to-noise ratio. All analyses were conducted at least five times. RSD was calculated between all ACV and CUR determinations.

\section{Precision}

Repeatability was determined by analyzing six different MP samples filled with ACV and CUR, all of them in the same day (Day 1, $n=6$ ). Intermediate precision was analyzed repeating the previous procedure in three different days $(\mathrm{n}=12$, where: Day 1, $\mathrm{n}=6$; Day 2, $\mathrm{n}=3$; Day 3, $\mathrm{n}=3$ ). Data are expressed as a function of the relative standard deviation (RSD\%) of a series of measurements.

\section{Accuracy}

Accuracy was evaluated by known drug concentrations recovering in a MP-Br sample. Samples of CUR and ACV standard solutions were added to $\mathrm{MP}-\mathrm{Br}$ in order to obtain 5, 10 , and $20 \mu \mathrm{g} \cdot \mathrm{mL}^{-1}$ of ACV and 5, 10, and $15 \mu \mathrm{g} \cdot \mathrm{mL}^{-1}$ of CUR. All samples were prepared as triplicates. Recovery percentage was evaluated.

\section{Robustness}

Methodology robustness was evaluated by means of minor and deliberated alterations of chromatographical conditions. The following parameters were altered: mobile phase $\left(\mathrm{ACN}: \mathrm{H}_{3} \mathrm{PO}_{4} \quad 0.1 \%: \mathrm{MeOH}\right)$ proportion $(52.5: 37.5: 10$ or $47.5: 42.5: 10)$, flow rate $\left(0.7\right.$ or $\left.0.9 \mathrm{~mL} \cdot \mathrm{min}^{-1}\right)$ and column temperature $\left(33\right.$ or $\left.37^{\circ} \mathrm{C}\right)$. Robustness confirmation was evaluated in terms of the RSD value obtained from determination at each condition when compared to the original setup.

\section{RESULTS AND DISCUSSION}

During the development of the analytical method, it has been tested different mobile phases to choose the most suitable chromatographic condition for ACV and CUR simultaneous determination. Initial tests were conducted with a binary mixture of $\mathrm{ACN}: \mathrm{H}_{3} \mathrm{PO}_{4} 0.1 \%$ (55:45), following previously related conditions (Moorthi, 2013b). However, those conditions resulted in a short retention time for ACV (1.94 min), being necessary to evaluate other mobile phase components proportion (40:60, 45:55, and 60:40). Nevertheless, the alterations that have been made did not resulted in a greater retention time for ACV neither in a proper resolution between CUR and other curcuminoids (bisdesmethoxycurcumin (CI) and demethoxycurcumin (CII)) (CUR 65\% purity).

Posteriorly, new assays were conducted based in another study (Jayaprakasha et al., 2002). In this step, the mobile phase was a ternary mixture of $\mathrm{ACN}: \mathrm{H}_{3} \mathrm{PO}_{4} 0.1 \%: \mathrm{MeOH}$ in different proportions (40:40:20, 50:30:20, and 50:40:10). Considering retention times for ACV (2.93 min) and CUR (11.57 min), and peaks resolution, it was choose as the most suitable mobile phase the mixture $\mathrm{ACN}: \mathrm{H}_{3} \mathrm{PO}_{4} 0.1 \%: \mathrm{MeOH}$ (50:40:10). Although these chromatographic conditions have not demonstrated suitable results for all of the parameters (Table 1), the obtained results were very similar to those in a previous study about simultaneous quantification (Simon, 2012; Moorthi, 2013b; Moorthi, 2013a).

Table 1: System suitability endpoints obtained by using the selected chromatographic conditions.

\begin{tabular}{lcccc}
\hline & Retention time & Resolution & Tailing & Theoretical plates \\
\hline ACV & 2.930 & - & 1.362 & 1147.40 \\
C I & 10.014 & 15.814 & 0.965 & 4784.61 \\
C II & 10.796 & 1.004 & 1.032 & 7872.19 \\
CUR & 11.573 & 1.459 & 1.004 & 7767.58 \\
\hline
\end{tabular}

ACV: acyclovir; CUR: curcumin; CI: curcuminoid I; CII: curcuminoid II.

The PDA detectors allow analysis of one or more substances at different wavelengths, as well as verification of the chromatographic peak purity. The purity of interest peaks in this work were 0.9998 and 0.9999 for ACV and CUR, respectively. These results indicate an adequate chromatographic separation between the drugs and most interferents. Figure 3 shows the obtained chromatogram at the selected conditions.

\section{Specificity}

Methodology specificity was evaluated by measuring its capacity of determining the drugs of interest in a mixture with their formulation excipients. Standard solution, MP and $\mathrm{MP}-\mathrm{Br}$ chromatograms (Figure 4) demonstrated that there was no interferent signal at the same retention time as the peaks of interest. Although there was an interferent at $3.42 \mathrm{~min}$, peak purity evaluation of ACV $(0.9998)$ has confirmed that it was not a hindrance for ACV efficient determination. 


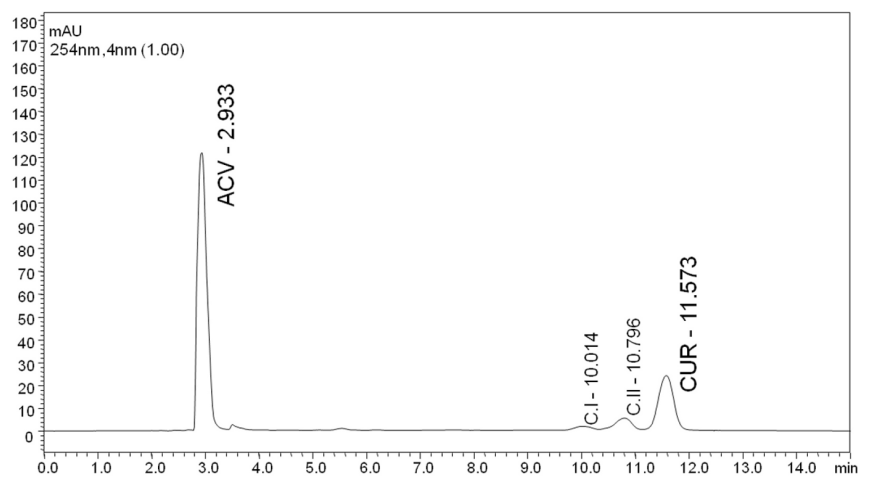

Fig. 3: Typical chromatogram obtained by utilizing the selected experimental conditions.
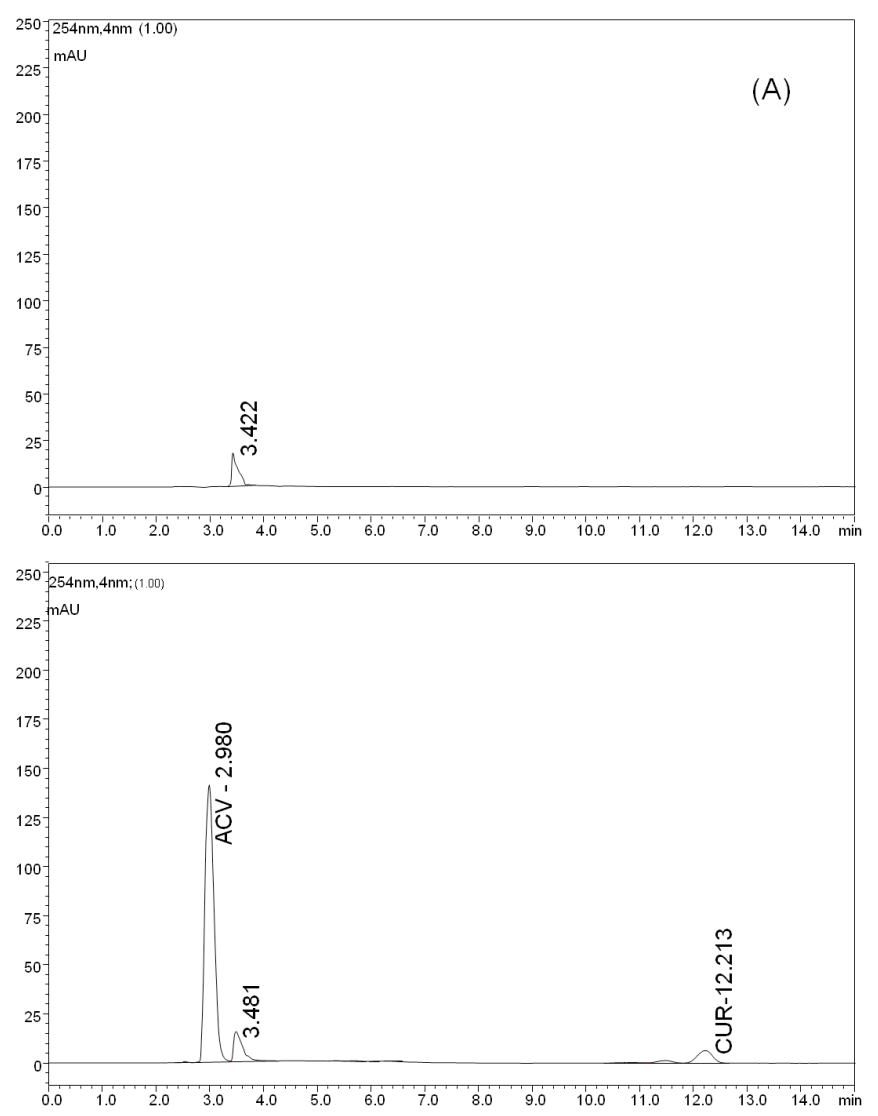

Fig. 4: Chromatogram obtained from a MP-Br sample (A) and from a sample containing ACV and CUR MPs (B).

\section{Linearity}

The linearity of the methodology was evaluated by plotting calibration curves for both the two drugs. The method showed to be linear in the range of 0.5 to $30 \mu \mathrm{g} \cdot \mathrm{mL}^{-1}$ for ACV and from 0.5 to $20 \mu \mathrm{g} . \mathrm{mL}^{-1}$ for CUR. Linearity coefficient was 0.9998 for ACV and 0.9999 for CUR, what asserts that the equipment response is indeed proportional to the drugs concentrations in the samples (ICH, 2005). The validity of the assays was verified by means of ANOVA, which demonstrated significant linear regression and no significant linearity deviation (Table 2).

Table 2: Results concerning methodology linearity and ANOVA analysis.

\begin{tabular}{lcc}
\hline & ACV & CUR \\
\hline Correlation coefficients & 0.9998 & 0.9999 \\
Line equations & $\mathrm{Y}=88644.5 \mathrm{x}-21551.8$ & $\mathrm{Y}=50042.2 \mathrm{x}-5508.3$ \\
Linearity range & $0.5-30 \mu \mathrm{g} \cdot \mathrm{mL}^{-1}$ & $0.5-20 \mu \mathrm{g} \cdot \mathrm{mL}^{-1}$ \\
Linear regression* & $\mathrm{F}_{\text {calculated }}=24700>\mathrm{F}_{\text {critical }}=$ & $\mathrm{F}_{\text {calculated }}=19700>\mathrm{F}_{\text {critical }}$ \\
& 4.96 & $=4.96$ \\
Linearity deviation* & $\mathrm{F}_{\text {calculated }}=0.71<\mathrm{F}_{\text {critical }}=3.33$ & $\mathrm{~F}_{\text {calculated }}=0.40<\mathrm{F}_{\text {critical }}=3.33$ \\
\hline
\end{tabular}

*Statistical significance $\alpha=0.05$; ACV: acyclovir; CUR: curcumin.

\section{Limit of detection (LOD) and quantification (LOQ)}

To determine the methodology sensitivity, LOD and LOQ were assessed. LOD values were $83.62 \mathrm{ng} \cdot \mathrm{mL}^{-1} \pm 3.59 \%$ for ACV and $91.61 \mathrm{ng} \cdot \mathrm{mL}^{-1} \pm 3.44 \%$ for CUR. While LOQ values were 109.52 ng. $\mathrm{mL}^{-1} \pm 1.16 \%$ for $\mathrm{ACV}$ and $128.71 \mathrm{ng} \cdot \mathrm{mL}^{-1} \pm$ $1.78 \%$, demonstrating that the method is sensible enough to determine ACV and CUR.

\section{Precision}

Repeatability and intermediate precision results are expressed as percentage of the drugs content, and also as RSD (Table 3 ). Repeatability assessment was conducted by analyzing six different samples at the same day, and the same experimental conditions. The RSD values were $0.98 \%$ for ACV and $1.41 \%$ for CUR. Intermediate precision was evaluated by a total amount of twelve analyzes for three consecutive days, where RSD values were $1.20 \%$ for ACV and $1.38 \%$ for CUR. Recovered content were about $96 \%$ and $97 \%$ for ACV and CUR, respectively, in all assays. All RSD values were lower than $2 \%$, what is within the established limits, asserting the methodology precision $(\mathrm{ICH}$, 2005).

Table 3: Content values for ACV and CUR, expressed as \% and RSD, representing repeatability and intermediate precision.

\begin{tabular}{lcc}
\hline & ACV & CUR \\
\hline Repeatability & \\
\hline Content (\%) & 95.81 & 97.32 \\
RSD day 1 & 0.98 & 1.41 \\
Content (\%) & 97.34 & 97.86 \\
RSD day 2 & 1.35 & 0.80 \\
Content (\%) & 95.93 & 96.33 \\
RSD day 3 & 0.44 & 1.46 \\
\hline & Intermediate precision \\
\hline Content (\%) & 96.22 & 97.21 \\
RSD intermediate & 1.20 & 1.38 \\
\hline
\end{tabular}

ACV: acyclovir; CUR: curcumin; RSD: relative standard deviation.

\section{Accuracy}

Accuracy has assessed recovery percentage after adding known amounts of ACV and CUR at three different concentrations on a MP-Br sample (Table 4). The developed method allowed 
recovery percentage close to $100 \%$ and RSDs lower than $2 \%$, asserting the methodology accuracy, according to the established standards (ICH, 2005).

Table 4: Percentage (\%) content values and RSD for ACV and CUR recovery at the three evaluated concentrations, representing method accuracy.

\begin{tabular}{lcc}
\hline & ACV (\%)* & CUR (\%)* \\
\hline Low concentration & $104.14 \pm 1.37$ & $103.30 \pm 0.31$ \\
Middle concentration & $103.29 \pm 1.84$ & $104.11 \pm 1.19$ \\
High concentration & $101.65 \pm 1.35$ & $101.84 \pm 1.91$ \\
\hline
\end{tabular}

* Values expressed as mean \pm RSD; ACV: acyclovir; CUR: curcumin; RSD: relative standard deviation.

\section{Robustness}

Deliberate and minor changes proposed to determine the methodology robustness revealed that, at the selected chromatographic conditions, there was no hindrance affecting both two drugs determination. The values for determination following each condition and their RSD values are presented in Table 5. It can observed that was no significant alteration regarding retention times and peak areas. Besides that, both two drugs content stood close to $100 \%$, and their RSD values were lower than $2 \%$ for all tested conditions. These data suggest that the methodology is robust in terms of mobile phase components ratio, flow variations, and temperature changes.

Table 5: ACV and CUR content and their respective RSD values following each chromatographic condition variation.

\begin{tabular}{lcccc}
\hline Condition & \multicolumn{2}{c}{ Retention time (min) } & \multicolumn{2}{c}{ Content (\%) } \\
\hline No changes & ACV & CUR & ACV & CUR \\
\hline Flow 0.9 mL.min ${ }^{-1}$ & 2.99 & 12.84 & 102.89 & 99.32 \\
Flow 0.7 mL.min ${ }^{-1}$ & 2.64 & 11.44 & 100.59 & 100.07 \\
Column temperature 32.5 $\mathrm{C}$ & 3.41 & 14.63 & 103.46 & 101.96 \\
Column temperature 37.5 $\mathrm{C}$ & 2.99 & 13.15 & 103.73 & 97.98 \\
Mobile phase ratio 52.5:37.5:10 & 2.98 & 12.54 & 104.71 & 100.45 \\
Mobile phase ratio $47.5: 42.5: 10$ & 2.97 & 10.27 & 100.35 & 98.59 \\
Mean & 2.95 & 14.50 & 99.60 & 103.42 \\
RSD & & & $\mathbf{1 0 2 . 0 7}$ & $\mathbf{1 0 0 . 4 1}$ \\
\hline
\end{tabular}

ACV: acyclovir; CUR: curcumin; RSD: relative standard deviation.

\section{CONCLUSIONS}

The developed HPLC methodology allowed simultaneous, simple and fast ACV and CUR determination. The results demonstrated that the method is specific for ACV and CUR, besides being linear, precise, accurate, and robust when considering the ICH determined standards, what allows it to be employed for these two drugs determination in complex carrier systems, such as polymeric microparticles.

\section{ACKNOWLEDGMENTS}

The authors thank CAPES (Brazil) for providing a master student fellowship.

\section{REFERENCES}

Brown SD, White CA, Chu CK, Bartlett MG. Determination of acyclovir in maternal plasma, amniotic fluid, fetal and placental tissues by high-performance liquid chromatography. J Chromatogr B Analyt Technol Biomed Life Sci. 2002; 772:327-334.

Fernandez M, Sepulveda J, Aranguiz T, von Plessing C. Technique validation by liquid chromatography for the determination of acyclovir in plasma. J Chromatogr B Analyt Technol Biomed Life Sci. 2003; 791: 357-363.

Field HJ, Vere Hodge RA. Recent developments in anti-herpesvirus drugs. Br Med Bull. 2013; 106: 213-249.

Gandhi A, Jana S, Sen KK. In-vitro release of acyclovir loaded Eudragit RLPO $((\mathrm{R}))$ nanoparticles for sustained drug delivery. Int $\mathrm{J}$ Biol Macromol. 2014; 67: 478-482.

Ghosh S, Sahu A, Kumar DS, Jena S, Harani A, Reddy TPK, Tanuja D. Method development and validation for acyclovir in tablet dosage form by RP-HPLC. J Pharm Res. 2012; 5: 785-1786.

International Conference of Harmonization- $\mathrm{ICH}$. Harmonized Tripartite Guideline Validation on Analytical Procedures: Text and Methodology. In: Q2(R1). Genova, 2005; 8-13.

Jayaprakasha GK, Jagan Mohan Rao L, Sakariah KK. Improved HPLC method for the determination of curcumin, demethoxycurcumin, and bisdemethoxycurcumin. J Agric Food Chem. 2002; 50: 3668-3672.

Joshi VA, Ahmed M G, Suresh S, kowti R. A Comparative Study: Solution Stability and Dissolution Behavior of Solid Dispersions Curcumin. Indian J Nov Drug Del. 2010; 2: 88-95.

Land G, Bye A. Simple high-performance liquid chromatographic method for the analysis of 9-(2-hydroxyethoxymethyl)guanine (acyclovir) in human plasma and urine. J Chromatogr. 1981; 224: 5158.

Li J, Jiang Y, Wen J, Fan G, Wu Y, Zhang C. A rapid and simple HPLC method for the determination of curcumin in rat plasma: assay development, validation and application to a pharmacokinetic study of curcumin liposome. Biomed Chromatogr. 2009; 23: 1201-1207.

Mandal SD, Mandal S, Patel J. Intranasal mucoadhesivemicroemulsion for neuroprotective effect of curcuminin mptp induced Parkinson model. Braz J Pharm Sci. 2017; 53:e15223.

Martins RM, Pereira SV, Siqueira S, Salomão WF, Freitas LAP. Curcuminoid content and antioxidant activity in spray dried microparticles containing turmeric extract. Food Res Int. 2013; 50: 657663.

Moorthi C, Kumar CS, Mohan S, Krishnan K, Kathiresan K. Application of validated RP-HPLC-PDA method for the simultaneous estimation of curcumin and piperine in Eudragit E 100 nanoparticles. J Pharm Res. 2013a; 7: 224-229.

Moorthi C, Kathiresan K. Reversed phase high performance liquid chromatographic method for simultaneous estimation of curcumin and quercetin in pharmaceutical nanoformulation. Int J Pharm Pharm Sci. 2013b; 5: 622-625.

Saxena A, Tewari G, Saraf SA. Formulation and evaluation of mucoadhesive buccal patch of acyclovir utilizing inclusion phenomenon. Braz J Pharm Sci. 2011; 47: 887-897.

Shahani K, Panyam J. Highly loaded, sustained-release microparticles of curcumin for chemoprevention. J Pharm Sci. 2011; 100: 2599-2609.

Simon A. Desenvolvimento e validação de método analítico por CLAE para quantificação simultânea de dipropionato de betametasona e fosfato sódico de betametasona em suspensão injetável. Quim Nova. 2012; 35: 593-600.

Stulzer HK, Tagliari MP, Murakami FS, Silva MA, Laranjeira MC. Development and validation of an RP-HPLC method to quantitate acyclovir in cross-linked chitosan microspheres produced by spray drying. J Chromatogr Sci. 2008; 46: 496-500.

Tung BT, Hai NT, Son PK. Hepatoprotective effect of Phy- 
tosome Curcumin against paracetamol-induced liver toxicity in mice. Braz J Pharm Sci. 2017; 53: 1-13.

Tzanavaras PD, Themelis DG. High-throughput HPLC assay of acyclovir and its major impurity guanine using a monolithic column and a flow gradient approach. J Pharm Biomed Anal. 2007; 43: 15261530 .

Wichitnithad W, Jongaroonngamsang N, Pummangura S, Rojsitthisak P. A simple isocratic HPLC method for the simultaneous determination of curcuminoids in commercial turmeric extracts. Phytochem Anal. 2009; 20: 314-319.

Yallapu MM, Jaggi M, Chauhan SC. Curcumin nanoformulations: a future nanomedicine for cancer. Drug Discov Today. 2012;
17: 71-80.

Zandi K, Ramedani E, Mohammadi K, Tajbakhsh S, Deilami I, Rastian Z, Fouladvand M, Yousefi F, Farshadpour F. Evaluation of antiviral activities of curcumin derivatives against HSV-1 in Vero cell line. Nat Prod Commun. 2010; 5: 1935-1938.

How to cite this article:

Reolon JB, Brustolin M, Haas SE, Bender EA, Malesuik MD,

Colomé LM. Development and validation of high-performance liquid chromatography method for simultaneous determination of acyclovir and curcumin in polymeric microparticles. J App Pharm Sci, 2018; 8 (01): 136-141. 